relatives in the actual programme. If such personal details had been merely workaday, perhaps complaint might have seemed less justified-but, among other things, it emerged that one man had been in prison and was now on probation; that a girl would be incapable of coping with the stresses of marriage; and that there were disagreements between the true parents and the houseparents of a hostel for mentally handicapped children over the management of a 6-year-old girl who was blind, spastic, and severely mentally handicapped.

This radio programme, which was designed for nurses in training, had the laudable aim of describing the role and scope of community care in mental illness and handicap. Nevertheless, it must be asked why far more care was not taken to disguise the patients presented in the case studiesas is done, for instance, in medical journals or in the B.B.C. television programme for doctors-by omitting the names of the hospitals concerned and obscuring some of the more obvious identifying features. In future doctors should ask themselves whether they are serving their patients' best interests by allowing hurtful and wounding details of such patients (who cannot give valid consent to such disclosure) to be discussed in a programme which is freely available to the public. And others concerned should remember the barrister's comments" in our ethics discussion: "Nurses and medical social workers who also have no contract with those under their care are equally bound by this equitable duty of confidence."

\footnotetext{
1 British Medical fournal, 1973, 2, 700.
Mental Illness and Handicap. London, B.B.C., 1973.
}

\section{Forcible Examination}

A public protest made in West Germany last week deserves some attention. According to a press report ${ }^{1}$ an alleged "urban guerilla leader" called Frau Ulrike Meinhof, aged 38 , is in a German prison awaiting trial. Eight years ago she had an operation for an intracranial tumour. Now the State prosecutor wants to have her medically examined to see whether she is fit to plead and can be held responsible for past actions. The examination proposed is said to entail the introduction of radioactive isotopes, and Frau Meinhof refuses to submit to it. The matter was therefore taken to court and finally reached the top in the Federal Constitutional Court. This ruled that the examination could be carried out, forcibly if necessary, even, according to the report," "with the use of a drug to overcome her resistance." It is against this decision that a group of West German intellectuals have protested.

They declare that the court's ruling contravenes the State's constitution. However that may be, the medical profession in West Germany should know that they will have the support of their colleagues in Britain in resisting any attempt to engage their members in the examination of a person against his or her will. Whatever the law may command in our respective countries, we share the same ethical tradition in medicine, and the forcible examination of a person is contrary to it. And the fact that the person is a prisoner would aggravate the offence. It is heartening, however, that this matter can be publicly ventilated in the Germany of today. In many countries, unfortunately, it still could not be.

1 The Times, 23 August 1973.

\section{The Cystic Meniscus}

Cysts of the menisci of the knee are not uncommon lesions. The lateral meniscus is affected three times as often as the medial meniscus and twice as often in men as in women. The cysts are usually multiple and situated in the peripheral part of the meniscus in its middle third. Some of the cysts may remain intracapsular, but larger cysts break through the capsule of the knee, especially on the outer side, and lie between it and the deep fascia, so that they may present as a painful or painless swelling. The cysts are usually distended with clear gelatinous material similar to that found in ganglia. Approximately half of all cystic menisci are associated with a damaged meniscus, possibly associated with the tethering effect of the cyst.

The aetiology of cystic menisci, like that of ganglia, is still not fully solved. I. S. Smilliel believes that a cyst derives from a degenerative process, the result of direct trauma, compression, or rotation, and adds his opinion that the condition tends to be confined to males of athletic age. B. $M$. Wroblewski ${ }^{2}$ in a review of 500 cystic menisci found that, though the commonest age of presentation was between the ages of $\mathbf{2 0}$ and $\mathbf{3 0}$ in men, patients' ages ranged from below $\mathbf{1 0}$ up to 80 . A history of trauma was present in only $37 \%$. Moreover, when there was a history of trauma, the chance of the meniscus being torn was $59 \%$; with no such history a meniscus tear was nevertheless present in $45 \%$. Wroblewski concludes that, though trauma plays a part, it does so by damaging the meniscus rather than by producing the cysts. The occasional finding of bilateral cystic menisci or of a familial occurrence adds further mystery to the aetiology.

Surgeons differ on the correct treatment. All are agreed that physiotherapy, injection of sclerosing fluid, or aspiration has no place. Some cysts associated with menisci which are presumably undamaged either do not give sufficient symptoms to warrant operation or spontaneously rupture and diminish in size or even disappear. For this reason some surgeons advocate that surgery should be limited to those patients with evidence of a torn meniscus, or, if it is lacking, that operation should be deferred for a time in the expectation that some cysts will disappear or become symptomless. Others advocate surgery for most patients whose symptoms are sufficiently troublesome. Removal of the cysts alone results in a high proportion of recurrence; removal of the meniscus alone leaves a swelling which may give rise to persistent discomfort. Complete removal of cysts and meniscus may sometimes be a difficult procedure, especially when the cyst is large and closely adherent to the capsule. But, if both have been adequately removed, recurrence is rare and the symptoms are usually relieved.

\footnotetext{
1 Smillie, I. S., Injuries of the Knee Foint, 4th edn. London, Churchill Livingstone, 1970

Wroblewski, B. M., Injury, 1973, 4, 319.
}

\section{Industrial Action and the B.M.J.}

The B.M.J. is among those publications affected by industrial action. We regret the inconvenience caused to our readers. 